\title{
Contribuições da teoria histórico-cultural para a formação das(os) professoras(es) alfabetizadoras(es): em busca do desenvolvimento do pensamento conceitual na atividade de ensino
}

\author{
Contributions of historical-cultural theory to the training of \\ literacy teachers: seeking the development of conceptual \\ thinking in teaching activity
}

Michelle de Freitas Bissoli ${ }^{1}$

Sônia Cláudia da Rocha Fonseca²

\section{Resumo}

Neste artigo, discute-se a construção de conceitos a partir de um processo formativo vivenciado por duas professoras alfabetizadoras, em Manaus (AM), com base em pesquisa de Doutorado, cujo objetivo geral foi analisar em que medida o processo formativo colaborativo desenvolvido pela pesquisadora se aproximou ou se distanciou da perspectiva de formação do pensamento conceitual postulado pela Teoria Histórico-Cultural (THC). A partir da análise dos dados gerados por meio de observação, autoscopia e grupo dialogal à luz das contribuições de Vygotski12 (2014) e outros autores da

\footnotetext{
$12 \mathrm{O}$ nome do autor aparece escrito de formas diferentes nas obras traduzidas e neste texto. Assim como na tese, optamos por grafá-lo conforme aparece na obra citada, preferindo usar a forma Vigotski, aportuguesada, quando não se trata de referências a obras consultadas.

${ }^{1}$ Possui graduação em Pedagogia (1996), Mestrado (2001) e Doutorado (2005) em Educação pela Faculdade de Filosofia e Ciências - UNESP/ Marília e Pós-Doutorado (2010) pela USP. Atualmente, é professor AssociadO III da Universidade Federal do Amazonas, onde atua no Núcleo de Estudos e Pesquisa em Educação e Infâncias e no Programa de Pós-Graduação em Educação.

${ }^{2}$ É Doutora em Educação (2017), pela Universidade Federal do Amazonas, Mestre em Ensino de Ciências na Amazônia (2008), pela Universidade do Estado do Amazonas e licenciada em Normal Superior (2006) pela mesma universidade, com complementação para o curso de Pedagogia (2011). É pesquisadora do Grupo de Estudo e Pesquisa em Teoria HistóricoCultural, Infância e Pedagogia.
}

Interfaces da Educ., Paranaíba, v.11, n.32, p. 326 - 352, 2020

ISSN 2177-7691 
THC, apresentou-se resultados que apontam possibilidades de desenvolver o pensamento conceitual de professores(as) alfabetizadores(as) a partir de um modelo de formação que: a) priorize a apropriação do conhecimento científico já produzido sobre alfabetização; b) parta das necessidades dos(as) professores(as) para criar novas necessidades e, c) considere o(a) professor(a) como protagonista, ou melhor, corresponsável pelo processo. Os resultados demonstram que, embora existam limites para o desenvolvimento de uma proposta que atinja o desenvolvimento do pensamento conceitual com as professoras, visto que se trata de um processo complexo e multideterminado, o diálogo permanente com os sujeitos e o investimento na formação do seu pensamento conceitual podem reverberar em mudanças na compreensão do processo de alfabetização e na prática dessas professoras.

Palavras-chave: Alfabetização. Formação de professores(as). Teoria Histórico-Cultural. Formação do pensamento conceitual.

\section{Abstract}

This article discusses the construction of concepts from a formative process experienced by two literacy teachers in Manaus (AM), based on doctoral research, with the general objective of analyzing to what extent the collaborative formative process developed by the researcher approached or distanced itself from the perspective of formation of conceptual thought postulated by the Historical-Cultural Theory (THC). From the data analysis generated by observation, autocopy and dialog group in the light of the contribution of Vygotski[1](2014) and other THC authors, results were presented that point to possibilities of developing the conceptual thinking of literacy teachers from a training model that: a) prioritizes the appropriation of scientific knowledge already produced on literacy, b) starts from the needs of teachers to create new needs and, c) considers the teacher as protagonist, or better, co-responsible for the process. The results show that, although there are limits to the developing of a proposal that reaches the conceptual thinking with the teachers, as it is a complex and multidetermined process, 
permanent dialogue with the subjects and investment in the formation of their conceptual thinking can reverberate in changes in the understanding of the literacy process and the practice of these teachers.

Keywords: Literacy. Teacher training. Historical-Cultural Theory. Formation of conceptual thinking.

\section{Introdução}

Neste trabalho, discutimos a formação de professores(as) que cuidam da alfabetização de crianças, a partir das contribuições da Teoria HistóricoCultural (THC), em uma perspectiva que consideramos humanizadora, no sentido de que possibilita maior apropriação das criações do gênero humano e o desenvolvimento que disso decorre em cada sujeito. Partimos do pressuposto de que a essência humana - ou aquilo que nos torna homens e mulheres - não nos é inata, mas é resultante de um processo de apropriação dos constructos materiais e simbólicos da cultura e de sua objetivação - da capacidade de nos expressar de maneira singular a partir de nossas apropriações (DUARTE, 1999; HELLER, 1987; VIGOTSKI, 2000; SĖVE, 1979). Sob esse ponto de vista, nossas capacidades especificamente humanas (VYGOTSKI, 2012) se desenvolvem à medida que (re-)produzimos as atividades desenvolvidas pelas outras pessoas, em um processo educativo (LEONTIEV, 1978) que nos possibilita progressivamente compreender o mundo, as relações sociais e a nós mesmos. Por isso, para a THC, educar é humanizar (LEONTIEV, 1978).

Professores e professoras são, nesse sentido, responsáveis por contribuir para a humanização das crianças. Por se tratar de um trabalho que requer objetivos claros, formas de atuar pedagogicamente que a eles corresponda, conhecimento acerca da(s) criança(s) e de seu processo de desenvolvimento, além do domínio da própria língua, alfabetizar é um trabalho que se localiza na esfera não-cotidiana da atividade humana e que exige do(a) professor(a) um envolvimento profundo de todas as suas capacidades (ou sua homogeneização), porque se trata de uma atividade que Interfaces da Educ., Paranaíba, v.11, n.32, p. 326 - 352, 2020 
requer meta-análise, ou a consciência da consciência (HELLER, 1987). Ensinar demanda, pois, uma intencionalidade que se funda em uma epistemologia, em um conjunto de objetivos e valores e, por isso, não pode ser uma atividade realizada sem um nível profundo de consciência (MELLO, 2000). Mas, isso somente será possível se também, como sujeitos, professores(as) puderem desenvolver ao máximo as suas capacidades especificamente humanas. Por isso, neste manuscrito, postulamos a necessidade de uma formação que possibilite, ao(à) professor(a) responsável por alfabetizar crianças, o desenvolvimento de suas máximas capacidades para a realização de seu trabalho para que, por meio dele, possa se humanizar cada vez mais, também como concerne ao trabalho na perspectiva marxiana (MARX, 2008). Portanto, com base na pesquisa de Doutorado desenvolvida, os argumentos defendidos neste manuscrito giram em torno do pressuposto de que o processo formativo deve priorizar a formação do pensamento conceitual dos(as) professores(as) alfabetizadores(as), por ser o tipo de pensamento necessário ao desenvolvimento da atividade de ensino, especialmente, neste texto, na alfabetização.

Nossa intenção é, tomando como referência os pressupostos da THC sobre a formação do pensamento conceitual e, considerando o objetivo geral da pesquisa de analisar em que medida o processo formativo colaborativo que desenvolvemos no período do doutorado se aproximou ou se distanciou dessa perspectiva, discutir como ocorre a formação de conceitos sob a perspectiva teórica que assumimos e sua importância para o processo formativo de professoras alfabetizadoras.

Cabe destacar que os dados utilizados neste trabalho foram resultantes do processo formativo colaborativo que vivenciamos na pesquisa empírica (2015-2016) de nosso processo de doutoramento ${ }^{2}$, com duas

\footnotetext{
2 Este trabalho apresenta parte dos resultados da pesquisa de doutorado, cuja tese foi defendida em outubro de 2017, no Programa de Pós-Graduação em Educação, da Universidade Federal do Amazonas (UFAM). Os dados aqui apresentados podem ser encontrados no terceiro capítulo da tese.
}

Interfaces da Educ., Paranaíba, v.11, n.32, p. 326 - 352, 2020 
professoras alfabetizadoras de uma escola municipal da cidade de Manaus (AM).

\section{Considerações sobre o processo formativo colaborativo desenvolvido na pesquisa}

Processo formativo colaborativo é como definimos o processo que conjugou pesquisa acadêmica e formação de professores(as), desenvolvido em nossa pesquisa de doutorado, que teve como princípios/eixos norteadores a participação das professoras nas tomadas de decisão e partir das necessidades das professoras para definição dos temas da formação. Nesse sentido, buscamos adequar as técnicas de observação (VIANA, 2007), autoscopia (SADALLA; LAROCCA, 2004), grupo dialogal (DOMINGUES, 2006), dentre outras técnicas às demandas próprias da pesquisa com sujeitos em formação, realizando um processo que tanto gerou dados para nossa pesquisa, como possibilitou momentos de desenvolvimento profissional aos sujeitos envolvidos.

Podemos dizer que, em síntese, esse processo formativo colaborativo constituiu-se por encontros entre pesquisadora e sujeito individualmente, e pesquisadora e sujeitos coletivamente, mediados por recursos como: vídeos das professoras realizando seu trabalho, textos de pesquisadores que estudam o processo de alfabetização e roteiros com questões para nortear o diálogo entre sujeitos com diferentes níveis de compreensão do objeto de estudo e diferentes objetivos.

Ao iniciarmos as atividades, em 2015, acreditávamos ser necessário ampliar as referências teóricas das professoras quanto ao processo de alfabetização das crianças e entendíamos ser fundamental partir das necessidades das próprias professoras, procurando ouvi-las e possibilitando sua participação no processo, considerando que os estudos mostravam que as formações para professores(as) desconsideravam esses aspectos (GATTI; BARRETO; ANDRÉ, 2011). No entanto, os estudos e as interlocuções que realizamos ao longo da pesquisa e do processo de doutoramento foram mostrando que as necessidades das professoras não eram necessariamente Interfaces da Educ., Paranaíba, v. 11, n.32, p. 326 - 352, 2020 
demandas delas, que tivessem sido geradas a partir de um processo de reflexão sobre as múltiplas determinações de seu trabalho na alfabetização, nem resultantes de sua práxis. Na verdade, tratava-se mais de "[...] falsas necessidades que o momento histórico lhe[s] impõe subliminarmente" (MELLO, 2000, p. 91) por meio, inclusive, dos processos formativos de que participaram (MORTATTI, 2008). O mesmo podemos dizer do modo como estávamos abordando o que chamamos de "conhecimento específico da alfabetização". Percebemos que, para além de considerar a historicidade da produção desses conhecimentos, precisávamos superar a aparente hegemonia que certos (pseudo)conceitos assumem (GONTIJO, 2014), para poder ter "condições de compreender o mundo dos profundos nexos que se ocultam por trás da aparência externa dos fenômenos" (VYGOTSKI, 2012, p. 64, tradução nossa).

Assim, tínhamos um duplo desafio a enfrentar: por um lado, problematizar com as professoras qual a origem das suas necessidades em relação ao trabalho que desenvolviam e, a partir disso, auxiliá-las a identificar necessidades humanizadoras, contrárias àquelas fundadas em exigências mercadológicas impostas à escola (FREITAS, 2014); ao mesmo tempo em que, por outro lado, desenvolvíamos conceitos a respeito do processo de alfabetização que as instrumentalizassem para a tomada de decisões autônomas e fundamentadas e que as capacitassem a refletir sobre as atividades propostas e desenvolvidas com as crianças com base em um conjunto de conhecimentos teóricos sobre o processo de alfabetização, que reverberassem em práticas intencionais.

Se compreendemos, apoiadas em Vygotski (2006), que um conceito não é apenas um conjunto de associações internamente relacionadas, mas que representa uma formação qualitativamente nova, um novo modo de atividade intelectual, uma nova forma de conduta em termos objetivos e subjetivos e que "[...] a linguagem não é o meio para expressar uma ideia já formada, mas para criá-la, não é o reflexo de uma concepção de mundo já estruturada, mas a atividade que a forma" (VYGOTSKI, 2006, p. 73, tradução nossa), restava-nos investir em um processo dialógico, que Interfaces da Educ., Paranaíba, v.11, n.32, p. 326 - 352, 2020 
permitisse a apropriação de conhecimentos pelas professoras a respeito de seu trabalho e a mudança consciente de seu posicionamento objetivo e subjetivo diante dele. Fundamentamo-nos no postulado de Vygostki (2006, p. 78-9), segundo o qual

\begin{abstract}
O pensamento em conceitos é o meio mais adequado para conhecer a realidade porque penetra na essência interna dos objetos, já que a natureza dos mesmos não se revela na contemplação direta de um ou outro objeto isolado, mas em meio aos nexos e relações que se manifestam na dinâmica do objeto, em seu desenvolvimento vinculado a todo o restante da realidade. O vínculo interno das coisas se descobre com a ajuda do pensamento em conceitos, já que elaborar um conceito sobre algum objeto significa descobrir uma série de nexos e relações do objeto dado com toda a realidade, significa inclui-lo no complexo sistema dos fenômenos.
\end{abstract}

Passemos, adiante, à discussão na qual defendemos processos formativos colaborativos que tenham como objetivo a formação do pensamento conceitual dos(as) professores(as) alfabetizadores(as).

\title{
A formação do(a) professor(a) alfabetizador(a) na perspectiva da formação do pensamento conceitual
}

A linguagem possibilitou ao homem operar mentalmente com o mundo dos objetos de forma abstrata, a partir dos significados que representam os objetos reais, sem que estes se apresentem imediatamente aos órgãos dos sentidos. Por isso, Mello (2000, p. 21) explica que "conhecer implica associar a percepção sensorial a um conceito [significado]" (MELLO, 2000 , p. 21). É essa função da linguagem que a torna fundamental para o processo de conhecimento, pois possibilita ao homem acessar o conhecimento anterior (tanto dele mesmo como das gerações precedentes) que se encontram sob a forma de conceitos.

O conhecimento é, então, resultado da internalização do mundo, da realidade concreta pelo sujeito que, por meio dos signos da cultura, tem a possibilidade de formar em seu pensamento a realidade abstrata. Portanto, quando falamos em formação de professores(as) alfabetizadores(as), estamos nos referindo a um processo que possibilite aos(às) professores(as) se 
apropriar dos conhecimentos culturais que lhes permitam idealizar o processo de alfabetização das crianças, que possam antecipar suas ações e refletir sobre elas, estabelecer relações, identificar problemas, conseguir explicá-los e buscar soluções.

Nesse sentido, o conhecimento sobre o processo de alfabetização possibilita ao(à) professor(a) alfabetizador(a) realizar sua ação no plano da realidade abstrata antes de intervir na realidade concreta (teorizar). Operando com os signos, especialmente com os conceitos, ele pode pensar sobre sua atividade e intervir de maneira cada vez mais transformadora na realidade concreta, desenvolvendo formas mais elaboradas de pensar e executar sua atividade para atender necessidades próprias do trabalho que realiza. Vygotski (2014) argumenta que o verdadeiro conhecimento passa pela apropriação do conceito.

Conceito para Vygotski (2014, p. 169-176, tradução nossa) é "uma série de atributos que são abstraídos" de determinado objeto ou fenômeno real e "se sintetizam de novo", convertendo-se "no significado, no sentido da palavra". Trata-se de uma generalização com base na abstração dos atributos nem sempre perceptíveis, mas essenciais, que são sintetizados em uma palavra e, "se converte[m] na forma fundamental do pensamento, através da qual a criança [na verdade, o adolescente] percebe e atribui sentido à realidade que o rodeia" (VYGOTSKI, 2016, p. 169). Portanto, o uso funcional da palavra é fundamental. A palavra "[...] sintetiza, simboliza o conceito abstrato e opera com ele como o signo superior entre todos os que já criou o pensamento humano." (VYGOTSKI, 2014, p. 169, tradução nossa).

Para os pensadores da THC, os conceitos mais elaborados são significados produzidos pelas ciências, pela filosofia, pelas artes e demais esferas da vida cultural, resultantes do processo histórico que representam o máximo conhecimento sobre a realidade já criado pelo gênero humano em cada campo específico de atuação humana (DUARTE, 1999; HELLER, 1987; PINO, 2005; VYGOTSKI, 2014). Podemos dizer, ainda, que não temos como nos apropriar dos conceitos científicos, filosóficos, artísticos e de nenhum outro por mera transmissão verbal ou descrições e demonstrações que não Interfaces da Educ., Paranaíba, v.11, n.32, p. 326 - 352, 2020 
tragam à tona a prática social envolvida no processo de sua formação. Faz-se necessário reproduzir a atividade que os gerou. É na atividade que descobrimos a função dos objetos, a prática social dos homens cristalizada neles e, portanto, sua verdadeira essência (LEONTIEV, 1978).

Nessa premissa está a justificativa para possibilitar a cada pessoa as condições de desenvolver o pensamento conceitual ou teórico, tendo em vista ser esse o tipo de pensamento mais desenvolvido do gênero humano e, por meio do qual é possivel transcender o imediatismo da realidade concreta, compreendendo a dinâmica de sua produção, assim como a possibilidade de sua transformação para atender as necessidades humanas.

Portanto, para desenvolver uma prática educativa escolar, tida como atividade não cotidiana, uma atividade extremamente complexa e multideterminada, é crucial que os(as) professores(as) desenvolvam esse tipo mais elaborado de pensamento - o pensamento conceitual - que tenha como base os conhecimentos científicos. Caso contrário, os(as) professores(as) podem formar uma imagem subjetiva superficial e alienada do processo de alfabetização e da realidade educacional (MELLO, 2000).

No entanto, a ênfase da formação de professores(as) tem recaído sobre discursos a respeito dos conceitos (CO-AUTOR et. al., 2016), como se fosse possivel recebê-los prontos e acabados, em processos formativos aligeirados e fragmentados, com ênfase no aspecto técnico da prática (MORTATTI, 2008; GONTIJO, 2014; CO-AUTOR, 2017). Esses processos não oferecem as condições necessárias para o desenvolvimento do pensamento conceitual, ou não foram intencionalmente pensados para esse fim. Nessas condições, torna-se mais fácil tomar o(a) professor(a) como mero aplicador de técnicas pensadas por outros (MORTATTI, 2008; LIBÂNEO, 2013). Além disso, os processos formativos oficiais, ao assumirem uma concepção teórica, tendem a se tornar hegemônicos e veiculam certas ideias em detrimento de outras, servindo a propósitos nem sempre humanizadores (GONTIJO, 2014).

No período em que realizamos a pesquisa, analisamos as propostas de formação de âmbito nacional, como o Pró-Letramento e o Pacto Nacional Interfaces da Educ., Paranaíba, v.11, n.32, p. 326 - 352, 2020 
pela Alfabetização na Idade Certa (PNAIC), os quais veiculavam, então, a concepção oficial de alfabetização do Ministério da Educação (MEC). Ambos desenvolveram propostas de formação apresentando a proposta "alfabetizar letrando", que parte do princípio de que:

[...] a entrada da criança (e também do adulto analfabeto) no mundo da escrita ocorre simultaneamente por esses dois processos: pela aquisição do sistema convencional de escrita - a alfabetização - e pelo desenvolvimento de habilidades de uso desse sistema em atividades de leitura e escrita, nas práticas sociais que envolvem a língua escrita - o letramento. Não são processos independentes, mas interdependentes, e indissociáveis [...]. (SOARES, 2004, p. 14, grifos da autora).

Para Gontijo (2014), essa concepção foi mais facilmente aceita pelos(as) professores(as) do que a concepção anterior, de Ferreiro e Teberosky (1999), de base construtivista. Para Ferreiro (2010, p. 21-22), "do ponto de vista construtivo, a escrita infantil segue uma linha de evolução surpreendentemente regular, através de diversos meios culturais, de diversas situações educativas e de diversas línguas". As autoras, portanto, apresentam uma explicação de como acontece essa evolução.

No entanto, Goulart (2014), assim como outros estudiosos, tem mostrado que, não raro, os(as) professores(as) têm se apropriado dos diferentes conceitos e propostas para o processo de alfabetização na escola de maneira esvaziada, resultando em práticas confusas (MELLO, 2000), uma vez que, os processos formativos que veiculam tais concepções não primam pela formação dos conceitos.

Não se trata aqui de superestimar o pensamento conceitual ou teórico como a única forma de pensamento válida, mas de, com base na perspectiva histórico-cultural, reconhecê-lo como o tipo de pensamento adequado à atividade de ensino, considerando que concordamos com o pressuposto de que se trata de uma atividade com alto grau de complexidade, que não pode ser captada em sua essência por outra via que não a do pensamento por conceitos.

É nessa perspectiva que se torna relevante a teoria da formação de conceitos de Vygotski (2014). Partindo de dados experimentais ricos Interfaces da Educ., Paranaíba, v.11, n.32, p. 326 - 352, 2020 
(considerando que investigou mais de 300 pessoas, entre crianças, adolescentes e adultos saudáveis e com comprometimentos intelectuais e verbais), ele identificou um progresso da formação de conceitos nas diferentes idades, chegando a concluir que:

[...] o desenvolvimento dos processos que podem dar lugar mais tarde à formação de conceitos tem suas raízes na primeira infância, porém, aquelas funções intelectuais cuja combinação constitui o fundamento psíquico do processo de formação dos conceitos amadurecem, se formam e se desenvolvem somente ao chegar à idade da puberdade. (VYGOTSKI, 2014, p. 130, grifos do autor, tradução nossa).

Vygotski (2014) identificou três fases principais no desenvolvimento dos conceitos que, por sua vez, apresentam vários momentos diferentes. Essas fases são: pensamento sincrético, pensamento por complexos e pensamento por conceitos.

Em linhas gerais, podemos dizer que o pensamento sincrético é próprio de crianças de pouca idade e bastante marcado pela tendência que elas possuem, nessa fase inicial da vida, para fundirem elementos completamente diferentes em uma imagem indiferenciada, com base em impressões perceptivas aleatórias. Por isso, por trás das palavras infantis está a imagem indiferenciada derivada de seu pensamento sincrético. No processo de desenvolvimento, esse tipo de pensamento aos poucos vai dando origem a uma nova forma, o pensamento por complexos.

A etapa que corresponde ao pensamento por complexos se desenvolve em um longo percurso, tendendo a começar na idade pré-escolar e seguir até a adolescência. É um passo muito importante na vida da criança, pois marca uma outra forma de relação com a realidade. Gradativamente, a criança vai superando a imagem sincrética, formada a partir de impressões perceptivas e subjetivas das coisas e começa a apresentar um pensamento coerente e objetivo, mesmo que não se possa compará-lo ao pensamento conceitual. Os complexos são construídos a partir das relações concretas e reais, enquanto os conceitos se estabelecem nas relações abstratas e lógicas.

Ao longo do percurso de desenvolvimento, o pensamento por complexos pode se apresentar de diferentes formas, mas, segundo Vygotski Interfaces da Educ., Paranaíba, v. 11, n.32, p. 326 - 352, 2020 
(2014), em situações de vida real, o pseudoconceito é a forma predominante do pensamento em complexos. Na verdade, em muitos casos, pode ser a única forma observável em crianças ainda na idade pré-escolar. Isso porque os complexos, que se relacionam com os significados das palavras, não se desenvolvem livremente, a partir de critérios da própria criança, como ocorreu na situação experimental, na qual os sujeitos operaram com palavras-conceitos inventados, sem conhecer previamente o seu significado. De fato, os complexos se formam a partir dos significados estáveis das palavras dados pelos adultos, ou seja, a fala dos adultos exerce papel diretivo na formação dos complexos.

Desse modo, os pseudoconceitos são os equivalentes funcionais dos verdadeiros conceitos. Ambos se referem ao mesmo repertório de objetos concretos, o que permite a comunicação verbal entre crianças ainda muito pequenas e adultos, pois possibilitam a compreensão mútua. No entanto, isso não significa dizer que essa equivalência observada no processo da comunicação verbal se estenda ao campo psíquico. Para Vygotski (2014), a generalização feita pela criança (pseudoconceito) coincide com a generalização baseada em conceitos apenas no resultado final; o modo de pensar da criança não pode ser equiparado ao modo de pensar do adulto, isso porque a primeira ainda não desenvolveu as estruturas que permitem a formação dos conceitos genuínos, o que faz com que seu pensamento seja baseado em pseudoconceitos próprios do pensamento por complexos, nos quais os significados das palavras ainda estão sendo desenvolvidos, bastante apoiados na experiência concreta (VYGOTSKI, 2014).

Além disso, essa fase que encerra o pensamento por complexos tem um extraordinário significado evolutivo no curso do desenvolvimento do pensamento. O pseudoconceito é o elo que liga pensamento por complexos e pensamento por conceitos. Ele "porta a semente do futuro conceito germinando em sem seu interior" (VYGOTSKI, 2014, p. 151).

Apesar de seu caráter transitório, intermediário entre pensamento sincrético e pensamento conceitual, o pensamento por complexos e, de forma especial, o pseudoconceito pode permanecer como modo de pensar Interfaces da Educ., Paranaíba, v. 11, n.32, p. 326 - 352, 2020 
também do adulto. Nas palavras do próprio Vygotski (2014, p. 164, tradução nossa):

Os pseudoconceitos não são patrimônio exclusivo das crianças. Nosso pensamento cotidiano se produz com grande frequência em forma de pseudoconceitos. Desde uma perspectiva dialética, os conceitos que aparecem em nossa fala habitual não são verdadeiros conceitos. São mais ideias gerais sobre as coisas.

Durante os encontros da pesquisa com formação, as falas das professoras acabaram revelando que elas intervinham no processo de alfabetização muito mais guiadas pelo pensamento empírico do que pelo pensamento por conceitos. Palavras, como por exemplo, "letramento" recebem das professoras um significado que não coincide com o(s) conceito(s) científico(s) elaborado(s) culturalmente, são mais ideias gerais ou pseudoconceitos. Para discutir essa afirmação, a título de exemplo, vamos analisar melhor um momento da primeira autoscopia individual com a professora Piedade. Nesse trecho, a professora avalia o resultado de sua aula videogravada, na qual podemos inferir pelo contexto de sua fala, os significados de algumas palavras que fazem parte da realidade do processo de alfabetização. Mas, para esse momento, vamos nos deter nas palavras "escrita" e "método silábico", cujos significados ficam mais evidentes:

Pesquisadora: Do que você havia planejado para essa aula, ela se desenvolveu do jeito que você pensou, que você planejou?

Professora Piedade: Não! Assim... até a parte oral [momento coletivo de interação verbal entre professora e crianças] foi mais ou menos como eu queria, mas, na escrita é que não foi, porque eles não se concentram para fazer. A escrita é que ainda, não... que eles não acompanham. Pode ver que a metade não faz a arte da escrita.

Pesquisadora: A tua proposta para essa aula era o quê?

Professora Piedade: A leitura e já a sequência de um texto. Porque não era totalmente a leitura, era o texto para depois trabalhar a questão das sílabas do C. [...] Porque a gente quase não trabalha mais o modo silábico. E eu sempre trabalhei com o modo silábico e essa mudança ainda não consegui sentir segurança.

[...]

Professora Piedade: A minha necessidade é identificar um método que atenda a eles. Eu ainda não encontrei um método que seja adaptável para eles. Porque eu vejo que o silábico não funciona. Porque na primeira semana, eu trabalhei o silábico com eles, que era o que eu dominava mais, mas não...

Pesquisadora: Como é o método silábico que você fala?

Interfaces da Educ., Paranaíba, v.11, n.32, p. 326 - 352, 2020 
Professora Piedade: Ele trabalha a palavra-chave, da palavra-chave há a construção de palavras, de outras palavras. Dessa construção de outras palavras você constrói pequenos textos, e aí há o desmembramento do texto e retorna para a construção de palavras, entendeu? Era dessa forma que eu trabalhava. Com eles não funcionou na primeira semana, nas duas primeiras semanas que eu fiquei. (AUTOSCOPIA INDIVIDUAL, 17/07/2015, grifos nosso)

Ao avaliar sua aula, a professora Piedade denomina de "escrita" o momento em que as crianças ficaram copiando o suposto texto "Letra C" do cartaz fixado no quadro. Assim, nesse momento de nosso diálogo, para ela, escrever significa copiar, ou seja, reproduzir no caderno os sinais gráficos que a criança vê no cartaz. Ela inclusive define como sendo "[...] a arte da escrita" (PROFESSORA PIEDADE, AUTOSCOPIA INDIVIDUAL, 17/07/2015), equivalendo ou aproximando o significado de "escrita" ao significado de "caligrafia".

No entanto, durante o processo formativo colaborativo, sempre usamos a palavra "escrita" para nos referirmos à linguagem escrita, a uma forma de objetivação humana, um instrumento cultural, um sistema de signos que tem função social ao mesmo tempo em que é função psicológica superior (VYGOTSKI, 2012). Portanto, ao usarmos a palavra "escrita" considerando sua função (e estabelecendo relações entre esta atividade e o seu significado para a sociedade e para o desenvolvimento do indivíduo que a domina - ou percebendo-a em sua essência), podemos dizer que seu significado expressa um conceito. Já no caso da professora Piedade, cabe destacar que ela se ateve aos aspectos externos da escrita (aquilo que o fenômeno de escrever revela à percepção imediata: o ato de grafar). Isso the possibilita uma generalização similar àquelas feitas pelas crianças, pautada na experiência empírica. Nesse sentido, ambas usamos a palavra "escrita", mas enquanto para nós essa palavra é o signo de um conceito científico, para a professora Piedade, se trata de um equivalente funcional, de um pseudoconceito que se refere ao mesmo objeto concreto, mas mobiliza formas diferentes de pensamento (VYGOTSKI, 2014). Nesse sentido, dialeticamente, se o fenômeno, o aspecto sonoro da palavra, revela parte da 
sua essência, não permite adentrar todas as relações que o caracterizam, somente acessiveis ao pensamento conceitual.

Quanto à expressão "silábico" usada pela professora para se referir ao método silábico, recorreremos primeiramente, ao trecho de nossos registros de observação no qual descrevemos os procedimentos usados por ela:

\begin{abstract}
Após entregar para cada criança uma ficha com uma palavra iniciada com $\mathrm{CA}, \mathrm{CO}, \mathrm{CU}, \mathrm{CE}$ ou $\mathrm{CI}$, a professora iniciou a aula explicando às crianças como seria a tarefa. Enquanto explicava, colocou no quadro um cartaz em papel madeira, com um texto intitulado "Letra C". Era um texto lacunado, com ilustrações sobre as lacunas que deveriam ser preenchidas por seus respectivos nomes. [...] A professora realizou uma leitura coletiva do texto (as crianças ajudavam identificando as ilustrações) e depois de algumas repetições, foi solicitando que as crianças que seguravam as palavras correspondentes às ilustrações trouxessem-nas para completar o cartaz [...]. Na sequência, a professora escreveu no quadro as silabas que estava trabalhando e foi chamando as crianças que ainda estavam com fichas. Cada criança que ia até o quadro, precisava observar a sílaba inicial da palavra de sua ficha e colocá-la abaixo da sílaba correspondente no quadro (figura 11) [...] (REGISTRO DE OBSERVAÇÃO, 14/07/2015).
\end{abstract}

Ao retomarmos a fala da professora, percebemos que ela usa a expressão "modo silábico" ou apenas "silábico" acertadamente para se referir a um método de alfabetização. O método silábico, ou método da silabação, é um dos métodos de marcha sintética, no qual se parte das famílias silábicas para iniciar o ensino da leitura e da escrita (MORTATTI, 2006). No entanto, apesar de a própria palavra "silábico" carregar em si parte de seu significado, quando relacionamos os dados do registro de observação e do discurso da professora, percebemos que ela parece não compreender que o método silábico corresponde a uma opção metodológica centrada na sílaba (essência). Pois, ao mesmo tempo em que declara quase não trabalhar mais com o método silábico, justificando que esse método não funcionou com sua turma, na prática, centra o processo de alfabetização das crianças no ensino das sílabas (reconhecimento da grafia e do som das sílabas de determinada letra em uma palavra).

A incoerência entre discurso e ação da professora não resulta de uma tentativa de mascarar a realidade. Pelo contrário, a professora Piedade Interfaces da Educ., Paranaíba, v.11, n.32, p. 326 - 352, 2020 
(assim, como a professora Anne) procurou ser sempre muito honesta em suas respostas e atos, deixando claro, ao longo da pesquisa com formação, que ela considerava necessário trabalhar com o enfoque na sílaba. Nesse caso, entendemos que o problema é realmente conceitual. Em algum momento de sua formação, a professora Piedade associou a expressão "método silábico" ao seguinte significado: "[método que] trabalha a palavrachave, da palavra-chave há a construção de [...] outras palavras. Dessa construção de outras palavras, você constrói pequenos textos, e aí há o desmembramento do texto e retorna para a construção de palavras" (PROFESSORA PIEDADE, AUTOSCOPIA INDIVIDUAL, 17 jul. 2015), que corresponde à descrição de um método analítico.

Considerando nossas vivências como professora alfabetizadora e a pesquisa bibliográfica que realizamos durante o doutorado, podemos dizer que esse não é um caso isolado. Nossos estudos acabaram mostrando as precárias condições da formação inicial e continuada dos(as) professores(as) alfabetizadores(as) para possibilitar a formação de um sistema de conceitos próprios da área, que lhes permita a apropriação/objetivação de conhecimentos sobre o processo de alfabetização. No modelo de formação adotado a partir das orientações de organismos internacionais, tanto o Próletramento como o Pacto Nacional pela Alfabetização na Idade Certa (PNAIC), que foram os processos formativos de âmbito nacional que correspondem ao período investigado, seguem o modelo cascata (GATTI; BARRETO, 2009), no qual, em última instância teremos formadores com praticamente o mesmo nivel de conhecimento dos(as) professores(as) em formação.

Assim sendo, detendo-nos ao contexto de nossa discussão, esses exemplos mostram que Vygotski (2014, p. 164, tradução nossa) está correto quando diz que "os pseudoconceitos não são patrimônio exclusivo das crianças".

Conforme o autor explica, a formação do conceito não se dá de maneira linear, fase pós fase. A sistematização proposta por Vygotski (2014) apresenta a sequência lógica resultante das condições artificiais criadas em seu experimento. Mas, o próprio pesquisador esclarece, em diferentes Interfaces da Educ., Paranaíba, v. 11, n.32, p. 326 - 352, 2020 
momentos de sua exposição, que na vida real as fases podem não se suceder como no experimento, ou mesmo não se manifestar, porque, em condições reais, as crianças se apropriam, ao seu modo, dos significados sociais das palavras, transmitidos pelos adultos em condições diversas e complexas da vida, que interferem no próprio curso do desenvolvimento infantil. Além disso, como vimos, mesmo quando adultos e já com a possibilidade de operar com conceitos, podemos continuar operando com complexos em determinadas atividades humanas, especialmente nas cotidianas (mas, como vimos, não somente nelas, revelando que atividades que requerem metaanálise nem sempre são realizadas com esse nível de consciência).

Assim, o pseudoconceito aparece como a forma mais elaborada de complexo a partir do qual surge o conceito genuíno. Isso significa dizer que se inicia, a partir dos pseudoconceitos, a terceira e última fase: o pensamento por conceitos.

Segundo Vygotski (2014, p. 165, tradução nossa), o conceito genuíno, já desenvolvido, "pressupõe não somente a união e a generalização de elementos isolados [pensamento por complexos], mas também a capacidade de abstrair; de considerar em separado esses elementos, fora das conexões reais e concretas dadas". Desse modo, o pensamento mais avançado, conceitual, também se apoia nos processos de análise e síntese. Mas isso acontece de forma mais complexa e sofisticada que nas fases anteriores.

Para Vygotski (2014), o conceito genuíno surge do processo de análise (abstração dos diversos atributos dos objetos, percebidos em separado), associado ao processo de síntese (quando os atributos se unem novamente) e quando essa dinâmica se converte na principal forma de pensamento da pessoa, passando a guiar a maneira como ela percebe e atribui sentido à realidade.

Tal desenvolvimento se completa apenas na adolescência. Porém, o início da adolescência marca o começo do processo de formação dos conceitos e ascensão a um tipo de pensamento superior aos tipos anteriores. Isso significa que os conceitos não estão acabados, mas em formação. Os adolescentes ainda têm grande dificuldade de transferência do conceito que Interfaces da Educ., Paranaíba, v.11, n.32, p. 326 - 352, 2020 
foi formado em dada situação concreta a novas situações. Por isso, Vygotski (2014, p. 172, tradução nossa) afirma que: "O caminho do abstrato ao concreto não é aqui menos dificil do que o foi em seu tempo de ascensão do concreto ao abstrato". Depois de formado, o conceito continua se desenvolvendo.

É importante destacar, ainda, que a formação do conceito não é um processo natural, mas ocorre em função das condições histórico-culturais, sem as quais o pensamento por complexos, especialmente na forma dos pseudoconceitos, pode permanecer como tal, sem evoluir para a formação de conceitos genuínos (VYGOTSKI, 2014), conforme vimos anteriormente, nos casos das palavras "escrita" e "[método] silábico".

Nesse sentido, se na idade pré-escolar o significado da palavra dado pelos adultos ocupa um papel diretor no desenvolvimento do pensamento por complexos, levando à formação dos pseudoconceitos, na adolescência, é por influência dos conceitos científicos advindos da instrução ${ }^{3}$ escolar que os pseudoconceitos podem se transformar em conceitos genuínos.

Para Vygotski (2014), os conceitos científicos correspondem aos conceitos produzidos no processo de instrução, no qual há veiculação do sistema de conhecimentos já produzidos pela humanidade. É no processo de formação do conceito científico tomando por base os conceitos cotidianos, construídos nas e pelas vivências, que as palavras imergem no concreto, formando o conceito genuíno. Por isso, Vygotski (2014) destaca a relevância dos conceitos científicos, afirmando-os como forma superior de conceito.

Assim sendo, o conceito científico é superior porque é social, sintese de múltiplas determinações, é histórico (recheado de atividade humana), por isso mesmo "o desenvolvimento do conceito científico de caráter social se produz nas condições do processo de instrução [...]" (VYGOTSKI, 2014, p. 183, tradução nossa). Porém, não é qualquer processo de instrução, ou em

\footnotetext{
${ }^{3}$ Segundo Prestes (2012), diferentes traduções de textos Vigotskianos para o português advieram de traduções anteriores para a língua inglesa. O conceito obutchenie, foi traduzido para o Português como aprendizagem, diferentemente do que expressa em russo. A palavra instrução é a que melhor se adequa ao conceito vigotskiano, que se refere à organização do trabalho pela escola para intervir sobre os processos de desenvolvimento, adiantando-se a eles. Utilizamos o termo instrução neste texto, corroborando essa posição.
}

Interfaces da Educ., Paranaíba, v.11, n.32, p. 326 - 352, 2020 
nosso caso, não é qualquer modelo de formação de professores(as) alfabetizadores que pode levar à formação dos conceitos científicos que possibilitem compreender o processo de alfabetização, mas, somente aquele que promove tensões, tarefas e problemas que exigem a atividade teórica do pensamento (MARTINS, 2011), especialmente porque os conceitos científicos são produzidos a partir de diferentes concepções teóricas e filosóficas, não são conceitos homogêneos.

Isso significa que em um processo formativo de professores(as) alfabetizadores(as) no qual se objetive o desenvolvimento do pensamento conceitual, é fundamental que as atividades promovam a apropriação de conceitos científicos já elaborados pelas diferentes perspectivas teóricas, desvelando o contexto histórico e ideológico em que eles foram/são produzidos e possibilitando a formação de um sistema de conceitos que permita, aos professores(as), refletir criticamente sobre o processo de alfabetização (sobre seu desenvolvimento, função social, potencial humanizador etc.).

A partir dessas considerações, refletiremos sobre o potencial do processo formativo colaborativo desenvolvido em nossa pesquisa, como um meio de desenvolvimento de conceitos sobre o processo de alfabetização de professores(as) alfabetizadores(as).

\section{O potencial do processo formativo colaborativo para o desenvolvimento do pensamento conceitual de professores(as) alfabetizadores(as)}

Apesar das condições reais em que se desenvolveu nossa pesquisa e considerando a necessidade imediata das professoras voltada para o caráter técnico, podemos dizer que o processo formativo colaborativo contribuiu para um movimento em direção à formação de conceitos no campo específico do processo de alfabetização. Essa conclusão surge em função de nossas observações e de elementos das falas das professoras, como podemos observar nesse exemplo trazido pela professora Anne, mostrando a mudança do significado da expressão "agrupamento na alfabetização". Ao avaliar a contribuição do processo formativo colaborativo, a professora relata: 
Professora Anne: [...] por exemplo, essa questão dos agrupamentos, [antes] quando eu fazia trabalhos em grupos eu não me preocupava em colocar por niveis [descritos na psicogênese da escrita] os grupos. Eu colocava aleatório. Eu achava até que era melhor colocar um que sabia muito com aquele que sabia pouco, mas na verdade não funciona. Porque só quem faz é o que sabe mais e o outro quase não faz nada, fica só esperando. E hoje em dia, quando eu faço isso... agora, por exemplo, uma vez na semana eu estou brincando de abecedário com eles em duplas, e coloco os que têm níveis próximos e sai muita coisa, que antes não saía. Então, eu vejo que é melhor, porque eles se preocupam mais em fazer. Tudo isso deu para refletir. (ENTREVISTA COLETIVA, 03/06/2016).

Nesse exemplo trazido pela professora Anne, podemos perceber que o conceito "agrupamento na alfabetização", a principio foi percebido pela atitude de obviedade, daquilo que os outros dizem que é, ou melhor, a professora se apropriou de um significado como pronto e acabado sem um processo de reflexão (ao assumir, pela primeira vez, uma turma em processo de alfabetização, a professora iniciou sua atividade seguindo as recomendações de sua mãe que é pedagoga e foi alfabetizadora). Porém, esse acabou se revelando como um pseudoconceito, ou seja, um falso conceito para a professora. Pela mediação do conhecimento científico, a partir da reflexão realizada no processo formativo colaborativo, a professora começou a operar com o conceito "agrupamento na alfabetização" a partir de outros parâmetros, inclusive, usando o critério da prática para validar esse novo conhecimento. Portanto, mesmo que a professora ainda não defina verbalmente o conceito, valendo-se de exemplos para expressá-lo (característica própria de um conceito recém formado), ela se apropriou de um novo conceito, que vai continuar se desenvolvendo. $\mathrm{E}$, a mudança de comportamento indica uma mudança no próprio pensamento (VYGOTSKI, 2014).

Consideramos que esse episódio, além de revelar o processo de formação de conceitos mediado pelo conceito científico, mostra também como a forma de pensar da professora guia sua ação e como essa ação interfere na atividade da criança em processo de alfabetização. Enquanto guiada pelo pensamento empírico, a professora organizava as crianças em 
agrupamentos de uma maneira que não permitia interações produtivas que contribuíssem para a alfabetização ("só quem faz é o que sabe mais e o outro quase não faz nada, fica só esperando").

Porém, quando a professora começa a operar com o conceito (pensamento conceitual) tem outra condição para agir no processo de alfabetização das crianças. Já instrumentalizada com o conceito, a professora consegue estabelecer outras relações entre o agrupamento das crianças e a alfabetização. Isso implica mudança na própria atividade da criança: aquela que ficava "só esperando", agora interage com as outras crianças e passa a ter uma atitude ativa quando se relaciona com o material escrito. Nas palavras da professora, "sai muita coisa, que antes não saía". Mas, na verdade, a mudança aconteceu antes no ensino, ou seja, o ensino conduziu a aprendizagem das crianças. Vygotsky (2005, p. 14) já declarava que: "o único bom ensino é o que se adianta ao desenvolvimento". Isso não representa uma correspondência direta entre ensino e aprendizagem, mas, na concepção aqui assumida, implica dizer que as aprendizagens que levam ao desenvolvimento intelectual característico dos humanos necessitam do processo de instrução.

Em nosso entendimento, o exemplo dado pela professora ilustra o real papel da formação de professores(as) frente aos outros tantos condicionantes do processo de alfabetização. Como estamos defendendo neste trabalho, a formação de professores(as) deve projetar e se adiantar ao desenvolvimento desejado e colocado em curso, ou seja, deve conduzir esse desenvolvimento. Portanto, ao mesmo tempo em que oportuniza aos(às) professores(as) a apropriação dos conhecimentos já produzidos pela ciência que lhes permitam intervir no processo de alfabetização das crianças, a formação deve possibilitar aos(às) professores(as) que se desenvolvam e se humanizem cada vez mais. Apesar de isso não ser tudo que se precisa para promover a alfabetização das crianças, fica claro que processos formativos que visem à formação do pensamento conceitual dos(as) professores(as) representam um salto qualitativo significativo nesse processo. A mudança de comportamento da criança - da passividade à atividade - durante o processo Interfaces da Educ., Paranaíba, v.11, n.32, p. 326 - 352, 2020 
de alfabetização, nesse episódio específico, não decorreu de mudanças de ordem interna da criança, muito menos de mudanças nas condições estruturais da escola ou na forma de acompanhamento da família. Nesse exemplo específico, a própria professora chega à conclusão de que o que mudou foi sua forma de conduzir o ensino, seu pensamento e consequente comportamento, resultantes de uma nova aprendizagem.

Nesse sentido, cabe retomar Aguerrondo (2002, p. 98) ao referir:

[...] os professores nem são culpados dos problemas da educação atual (sem que por isso sejam inocentes) nem são nem podem ser os atores singulares do melhoramento da educação, pois são muitos os fatores que contribuem para produzir seus resultados. Porém, indubitavelmente, são atores que têm um papel central a cumprir e esse papel depende do maior ou menor grau em que se sintam, exerçam e sejam reconhecidos como profissionais da educação.

Portanto, se opor à tese neoliberal que visa a responsabilizar os(as) professores(as) pelos resultados da educação (sejam eles bons ou ruins), não é, em hipótese alguma, colocá-los na condição de vítimas ou heróis, mas situá-los como sujeitos que têm um importante papel a cumprir. Seu trabalho é indispensável para a educação e desenvolvimento das crianças. Mas, para tanto, precisam compreender o que ensinam, para quem ensinam, por que ensinam e como ensinam e, para isso, precisam se apropriar dos conhecimentos/conceitos já produzidos sobre o processo de alfabetização.

\section{Considerações finais}

Considerando os condicionantes histórico-culturais, entendemos que, apesar das muitas dificuldades que necessitamos superar para implementar um processo formativo colaborativo como o que tentamos empreender na escola, ele tem grande potencial de desenvolver o pensamento conceitual dos(as) professores(as). Porém, é necessário mudar a concepção e os objetivos da formação de professores(as) alfabetizadores(as), valorizando mais os sujeitos da formação e aproveitando melhor os espaços e os tempos já institucionalizados para esse fim na própria escola. É necessário implementar processos formativos que sejam contínuos, como parte da Interfaces da Educ., Paranaíba, v.11, n.32, p. 326 - 352, 2020 
rotina dos(as) professores(as). Pois as necessidades mais aparentes, como as que envolvem o caráter técnico, precisam ser superadas; novas necessidades precisam ser criadas, motivadas pelo aprofundamento do estudo teórico, uma vez que não é possivel formação de conceitos em processos aligeirados sem a devida mediação dos conhecimentos científicos.

Por isso, é fundamental a mediação de um formador que, ao ter alcançado o nivel de conhecimento esperado dos(as) professores(as) em formação, possa fazer o papel de portador dos signos da cultura (no caso discutido aqui, portador do conhecimento científico sobre alfabetização). $\mathrm{Na}$ perspectiva histórico-cultural, essa é uma condição necessária ao desenvolvimento humano. É a intervenção do portador de signos que transforma o meio (processos formativos) em fonte de desenvolvimento para os(as) professores(as) (VIGOTSKI, 2010; MELLO, 2010, VIGOTSKI, 2018). Provavelmente, esse é o principal limite a ser superado pela escola para promover processos formativos colaborativos, que tenham por objetivo o desenvolvimento do pensamento conceitual dos(as) professores(as).

Em nosso trabalho, estamos focalizando a formação do(a) professor(a), mas, na verdade, assim deveria ser o processo educativo das pessoas desde a infância. Em uma situação ideal, todos deveriam ter o direito à aprendizagem garantindo o desenvolvimento das formas mais complexas de pensamento ao longo da vida. Direito às aprendizagens que possibilitassem o desenvolvimento máximo das capacidades de cada pessoa. Em um plano ideal, todas as pessoas deveriam ter acesso e oportunidades iguais de se apropriar das criações humanas já alcançadas historicamente. E, nas instituições de ensino (básico e superior), nos processos formativos institucionalizados (formação inicial ou continuada), isso significa direito de se apropriar dos conhecimentos criados e organizados pela humanidade, eleitos como os mais relevantes para a sua atuação no meio em que vivem, ou para construir aquela sociedade que idealizam.

No entanto, em uma sociedade de classes como a nossa, na qual as condições de vida e educação das pessoas são tão desiguais e dependem da classe que detém o poder político e econômico, estamos submetidos em Interfaces da Educ., Paranaíba, v. 11, n.32, p. 326 - 352, 2020 
menor ou maior grau às diretrizes dessa classe que não tem como prioridade o desenvolvimento omnilateral das pessoas (DUARTE, 2001). Os processos formativos e as condições concretas de vida são determinantes para que as pessoas possam se apropriar plenamente das propriedades humanas em suas formas mais elaboradas, como é o caso do pensamento conceitual e da cultura escrita, cujo desenvolvimento se dá no bojo dessas condições.

É necessário sempre levar em consideração que as funções psíquicas superiores, propriamente humanas, não se desenvolvem pelo processo de maturação do organismo, mas pelo processo de apropriação dos constructos materiais e simbólicos e pela objetivação (expressão dos sujeitos mediada pelos elementos dos quais se apropriou) em atividades que necessitem dessas funções para se realizar (VYGOTSKI, 2014). Portanto, trata-se de um longo processo de interação entre pessoas que já formaram as funções e aquelas que precisam se apropriar delas. E essas interações ocorrem em situações reais e concretas de existência em uma sociedade de classes.

Assim, os processos formativos de professores(as), em especial, de alfabetizadores, além de se preocupar com o conteúdo da formação, necessitam, ainda, considerar os sujeitos que vivenciam as formações, levar em consideração as condições em que os(as) professores(as) se apropriaram dos significados das palavras, com as quais se comunicam os conhecimentos já produzidos sobre o processo de alfabetização. É necessário entender que tais significados podem não estar completamente desenvolvidos, levando à atribuição de sentidos diametralmente diferentes aos significados sociais criados sobre o processo de alfabetização. Disso depende a efetiva formação dos(as) professores(as) alfabetizadores, uma formação que seja desenvolvente para o próprio sujeito e para aqueles com os quais ele interage durante sua atividade de ensino.

\section{Referências}

AGUERRONDO, I. Los desafios de la política educativa relativos a las reformas de la formación docente. In: CONFERENCIA EL DESEMPEÑO DE MAESTROS EN AMÉRICA LATINA Y EL CARIBE: Nuevas Prioridades, 2002, Brasília: UNESCO/MEC/BID, jul. 2002. 
AUTOR et. al., 2016.

CO-AUTOR, 2017.

DOMINGUES, I. Grupos dialogais: compreendendo os limites entre pesquisa e formação. In: PIMENTA, S. G.; GHEDIN, E.; FRANCO, M. A. S. (Org.). Pesquisa em educação: alternativas investigativas com objetos complexos. São Paulo: Edições Loyola, p. 165-182, 2006.

DUARTE, N. A individualidade para-si: contribuição a uma teoria históricosocial da formação do indivíduo. Campinas: Autores Associados, 1999.

DUARTE, N. Vigotski e o "aprender a aprender": crítica às apropriações neoliberais e pós-modernas da teoria vigotskiana. 2. ed. rev. e ampl. Campinas, SP: Autores Associados, 2001. (Coleção educação contemporânea). Disponível em: <http:/ / xa.yimg.com/kq/groups/23100729/756321344/name/Vigotski\%25 $20 \mathrm{e} \% 2520$ o\%2520aprender\%2520a\%2520a\%2520prender.pdf>. Acesso em 20 mar. 2013.

FERREIRO, E. Reflexão sobre alfabetização. 25. ed. São Paulo: Cortez, 2010. (Coleção questões da nossa época; v. 6).

FREITAS, L. C. de. Os reformadores empresariais da educação e a disputa pelo controle do processo pedagógico na escola. Educação \& Sociedade, v. 35, n. 129, p. 1085-1114, Out./Dez. 2014.

GATTI, B. A. (org.); BARRETTO, E. S. de S. Professores do Brasil: impasses e desafios. Brasília: UNESCO, 2009.

; BARRETTO, E. S. de S.; ANDRÉ, M. E. D. de A. Politicas docentes no Brasil: um estado da arte. Brasília: UNESCO, 2011.

GONTIJO, C. M. M. Alfabetização: politicas mundiais e movimentos nacionais. Campinas, SP: Autores Associados, 2014.

GOULART, C. M. A. O conceito de letramento em questão: por uma perspectiva discursiva da alfabetização. Bakhtiniana, São Paulo, v. 9, n. 2, p. 35-51, Ago./Dez. 2014.

HELLER, A. Sociologia de la vida cotidiana. Barcelona: Edicions 62, 1987.

LEONTIEV, A. N. O homem e a cultura. In: O desenvolvimento do psiquismo. Lisboa: Livros Horizonte, 1978. p. 259-284. 
LIBÂNEO, J. C. Licenciatura em pedagogia: a ausência dos conteúdos específicos do ensino fundamental. In: GATTI, B. A. et al. (orgs.). Por uma política nacional de formação de professores. São Paulo: Editora Unesp, 2013.

MARTINS, L. M. B. O desenvolvimento do psiquismo e a educação escolar: contribuições à luz da psicologia histórico cultural e da pedagogia histórico-crítica. 2011. Tese (Livre docência) - Universidade Estadual Paulista, Bauru, 2011.

MARX, Karl. Manuscritos econômicos e filosóficos. Trad. Jesus Ranieri. 2 ed. São Paulo: Boitempo, 2008.

MELLO, S. A. Linguagem, consciência e alienação: o óbvio como obstáculo ao desenvolvimento da consciência crítica. Marília: Unesp Marília Publicações, 2000.

A questão do meio na pedologia e suas implicações pedagógicas. Psicologia USP, São Paulo, v. 21, n. 4, 2010, p. 727739. Disponivel em: http://www.scielo.br/pdf/pusp/v21n4/v21n4a05.pdf >. Acesso em 16 jun. 2013.

MORTATTI, M. do R. L. História dos métodos de alfabetização no Brasil. In: SEMINÁRIO ALFABETIZAÇÃO E LETRAMENTO EM DEBATE, 2006, Brasília. Anais eletrônicos. Brasília: Secretaria de Educação Básica do Ministério da Educação, 2006, p. 1-16. Disponivel em: <http://portal.mec.gov.br/ seb/arquivos/pdf/Ensfund/alf_mortattihisttextalfbbr.pd> Acesso em 28 jan. 2009.

Notas para uma história da formação do alfabetizador no Brasil. Revista Brasileira de Estudos Pedagógicos, Brasília, v. 89, n. 223, p. 467476, set.-dez. 2008.

PINO, Angel. Natureza cultural do psiquismo humano: aspectos teóricos. In: As marcas do humano: às origens da constituição cultural da criança na perspectiva de Lev S. Vigotski. São Paulo: Cortez, 2005. p. 43-112.

PRESTES, Z. Quando não é quase a mesma coisa: traduções de Lev Semionovitch Vigotski no Brasil. Campinas: Autores Associados, 2012.

SĖVE, L. Marxismo e a Teoria da Personalidade. Lisboa: Horizonte Universitário, 1979. 3 vol.

SADALLA, A. M. F. de A.; LAROCCA, P. Autoscopia: um procedimento de pesquisa e de formação. Educação e Pesquisa, São Paulo, v. 30, n. 3, p. 419- 
433, set.-dez., 2004. Disponivel em: $<$ http://www.redalyc.org/articulo.oa?id=29830303> acesso em: 04 nov.2014.

SOARES, M. B. Letramento e alfabetização: as muitas facetas. Rev. Bras. Educ., Rio de Janeiro, n. 25, Apr. 2004. Disponível em: <http://www.scielo.br/ scielo.php? script=sci_arttext\&pid=S1413$24782004000100002 \& \operatorname{lng}=\mathrm{en} \& \mathrm{nrm}=$ iso $>$. Acesso em: 16 mar. 2013.

VIANNA, H. M. Pesquisa em educação: a observação. Brasília: Líber Livro Editora, 2007.

VIGOTSKI, L. S. Manuscrito de 1929. Educação e Sociedade, Campinas, vol. 21, n.71, p. 21-44, 2000.

VIGOTSKI, L. S. A questão do meio na pedologia. Tradução de Márcia Pileggi Vinha. Psicologia USP, São Paulo: USP, V. 21, n. 4, p. 681-701, 2010.

VIGOTSKI, Lev Semionovich. Sete aulas de L. S. Vigotski sobre os fundamentos da pedologia. Organização [e tradução]: Zoia Prestes e Elizabeth Tunes; tradução: Cláudia da Costa Guimarães Santana. Rio de Janeiro: E-Papers, 2018.

VYGOTSKI, L. S. Obras escogidas IV. Madrid: Machado Libros, 2006.

Obras escogidas III. Madrid: Machado Libros, 2012.

Obras escogidas II. Madrid: Machado Libros, 2014.

VYGOTSKY, L. S. Aprendizagem e desenvolvimento intelectual na idade escolar. In: LEONTIEV, A. N. et al. Psicologia e pedagogia: bases psicológicas da aprendizagem e do desenvolvimento. Tradução Rubens Eduardo Frias. 3. ed. São Paulo: Centauro, 2005. 